\title{
Evaluation of the Influence of Microwaves in the Structure of Silica Gels
}

\author{
Gisele M. Neves, Rubia F.S. Lenza*, Wander L. Vasconcelos \\ Laboratory of Ceramic Materials - LMC \\ Dept. of Metallurgical and Materials Eng. - UFMG \\ Rua Espírito Santo 35, 2o andar - Centro, Belo Horizonte - MG, Brazil
}

Received: November 16, 2001; Revised: July 14, 2002

\begin{abstract}
In this work we studied the influence of microwaves in the pore structure of silica gels obtained via sol-gel polymerization process. We analised the feasibility of replacing conventional heating by microwave heating during drying. Structural parameters such as specific volume of pores $\left(\mathrm{V}_{\mathrm{p}}\right)$, specific surface area $\left(\mathrm{S}_{\mathrm{p}}\right)$, average pore size $\left(\mathrm{r}_{\mathrm{p}}\right)$ and the bulk and true densities were measured. X-ray diffraction confirmed the obtention of a completely amorphous structure for the gels. Some characteristics of silica gels were evaluated by thermogravimetric analyses (TGA), differential thermal analyses (DTA) and Fourier transform infrared spectroscopy (FTIR). We observed that microwave drying is a feasible process to yield controlled pore nanostructures. The gels obtained via microwave heating presented average pore size of $1.2 \mathrm{~nm}$, specific surface area of $112 \mathrm{~m}^{2} / \mathrm{g}$ and specific volume of pores of $0.06 \mathrm{~cm}^{3} / \mathrm{g}$. The gels obtained via conventional heating presented average pore size of $1.3 \mathrm{~nm}$, specific surface area of $748 \mathrm{~m}^{2} / \mathrm{g}$ and specific volume of pores of $0.49 \mathrm{~cm}^{3} / \mathrm{g}$.
\end{abstract}

Keyswords: structure, sol-gel and microwave

\section{Introduction}

The microwave processing makes possible to heat both small and large pieces very rapidly and uniformly, to efficiently remove volatile constituents (binders, moisture, etc) from thick sections. The absorption of microwave energy varies with the composition and structure of different phases, being possible the selective heating ${ }^{1-3}$.

Microwave heating is fundamentally different from conventional heating processes. In the microwave process, heat is generated internally within the material, instead of originating from external heating sources. As a result of this internal and volumetric heating, smaller thermal gradients are created in microwave-processed materials than in materials processed by conventional heating, reducing cracking during drying ${ }^{4}$.

Another advantage of microwave heating is that the treatment time can be considerably reduced, which in many cases represents a reduction in the energy consumption as well ${ }^{4}$.

Sol-gel is a low temperature method using chemical precursors that produces ceramics and glasses with better purity and homogeneity than high temperature conventional process. One major characteristic of sol-gel process is a large variety of pore structures (average pore size, pore size distribution, surface area, porosity, etc) that occur during processing and in the final product. The control of pore structures in every stage of the process is of great interest, since controlling the pore structure is very important in order to achieve specific physical properties of products, such as index of refraction and capacity of adsorption ${ }^{5,6}$.

A major concern in the production of monolithic dried gels is the prevention of cracks during aging and drying steps. As the solvent escapes from within the gel or as the pore size changes during these processes, stresses are introduced into the silica network which may cause fracturing 7,8 .

Microwave processing has promising results when used for drying and densification of sol-gel silica ${ }^{4,9,10}$. The liquid precursor is removed by means of the electromagnetic field associated to the microwaves. It was observed that microwaves affect not only the surface area and porosity but also adsorption isotherms ${ }^{10}$.

Mesoporous material has been prepared in very short crystallization time using microwave heating. Using microwave radiation during synthesis provides a way to control the crystallinity of gels according to the selection of syn-

*e-mail: rulenza@zipmail.com.br

Trabalho apresentado no $\mathrm{XX}^{\circ}$ CBECIMAT, Águas de São Pedro,

Dezembro de 2000 
thesis parameters ${ }^{11}$. Dense, foam-free, optically transparent gel-derived silica monoliths were produced using microwave energy. The heating produced by microwave energy allowed high heating rates, fast dehydration and rapid densification $^{12}$.

The exact way in which the microwave radiation affect the structural parameters of sol-gel materials are still unclear. It is important that the effect of microwaves in materials properties becomes well understood in order to make this process a reliable and practical technology for industrial applications. Thus, the goal of this work is to study the influence of microwaves in the structure of silica obtained by sol-gel method during drying.

\section{Experimental Procedure}

The chemical precursor used in the fabrication of silica gels was tetramethyl ortosilicate (TMOS, Aldrich Corp.). Nitric acid was used as catalyser. Porous silica obtained via conventional heating was aged and dried inside conventional open to air oven (model 315SE, FANEN). Porous silica obtained via sol-gel polymerization process was aged and dried using open to air microwave oven (MDS 2100, CEM).

Structural characteristics of silica gels were obtained using nitrogen adsorption-desorption analyses. The equipment used was an Autosorb-1 (Quantachrome). The average pore radius $\left(r_{p}\right)$ was estimated from $r_{p}=2 V_{p} / S_{P}$, were $\mathrm{V}_{\mathrm{p}}$ is the specific pore volume and $\mathrm{S}_{\mathrm{p}}$ is the specific surface area $^{13}$. The data on true density $\left(\rho_{t}\right)$ were obtained from helium pycnometry experiments, using Pycnometer Multivolume (model 1305, Quantachrome). Bulk density measurements were carried out using two different methods: mercury pycnometry and nitrogen adsorptiondesorption analyses. The metric properties used for geometric description were volume fraction of pores $\left(\mathrm{V}_{\mathrm{v}}\right)$ and the surface area density $\left(\mathrm{S}_{\mathrm{v}}\right)$. These properties were obtained by nitrogen adsorption-desoption analyses. The connectivity of pores per unit volume $\left(\mathrm{G}_{\mathrm{v}}\right)$ was evaluated using a cylindrical model developed by Vasconcelos ${ }^{6,14}$. In that model, the expression used to evaluate the genus is obtained through correlating of the metric properties $\mathrm{S}_{\mathrm{v}}$ and $\mathrm{V}_{\mathrm{v}}$, as follows ${ }^{6}$ :

$$
G_{v}=\frac{S_{v}{ }^{3}}{\left(32 \pi V_{v}\left(1-V_{v}\right)\right)}+1
$$

The thermal behavior of the gels was evaluated using thermogravimetric analyses (TGA- 50, Shimadzu) and differential thermal analyses (DTA-50, Shimadzu). Fourier transform infrared spectroscopy (DRFTIR) was carried out using an equipment FTIR Paragon - 1000 (Perkin - Elmer) with the software Spectrum for Windows 1.0.

\section{Results and Discussion}

Table 1 presents the bulk density measurements from mercury pycnometry and nitrogen adsorption-desorption and also the true density obtained by helium pycnometry.

The data on bulk density obtained for conventionally heated samples by nitrogen adsorption-desorption analyses and helium pycnometry were smaller than the values obtained using mercury pycnometry. This difference can be a result of the errors associated with the determination of true density through helium pycnometry due to the difficulty to evaluate the real weight of samples, since can occur the presence of water molecules adsorved in their surfaces e into their pores. The difference is only $8 \%$, thus we used the estimated bulk density values to compare the samples properties. We observed that the bulk density is bigger for porous silica made via microwave heating.

The nitrogen adsorption-desorption isotherms for porous silica obtained via conventional and microwave heating are shown in Figs. 1 and 2, respectively. According to de Boer definition ${ }^{15}$, the isotherm obtained via conventional heating is type I isotherm, being characteristic of a microporous solid (pore radii $\leq 1.5 \mathrm{~nm}$ ) and represent cylindrical pores opened in both extremities, in agreement with

Table 1. Values of bulk density $\left(\mathrm{r}_{\mathrm{v}}\right)$ and true density $\left(\mathrm{r}_{\mathrm{t}}\right)$ for porous silica obtained via conventional heating and microwave heating.

\begin{tabular}{lccc}
\hline Material & $\begin{array}{c}\mathrm{r}_{\mathrm{t}} \\
\left(\mathrm{g} / \mathrm{cm}^{3}\right)\end{array}$ & $\begin{array}{c}\mathrm{r}_{\mathrm{v}}(\mathrm{Hg}) \\
\left(\mathrm{g} / \mathrm{cm}^{3}\right)\end{array}$ & $\begin{array}{c}\mathrm{r}_{\mathrm{v}}\left(\mathrm{N}_{2}\right) \\
\left(\mathrm{g} / \mathrm{cm}^{3}\right)\end{array}$ \\
\hline conventional & $1.41 \pm 0.05$ & $1.22 \pm 0.01$ & $1.12 \pm 0.02$ \\
microwave & $1.82 \pm 0.05$ & - & $1.62 \pm 0.06$ \\
\hline
\end{tabular}

$(\mathrm{Hg})$ : mercury pycnometry

$\left(\mathrm{N}_{2}\right)$ : estimated from $\mathrm{N}_{2}$ adsorption-desorption

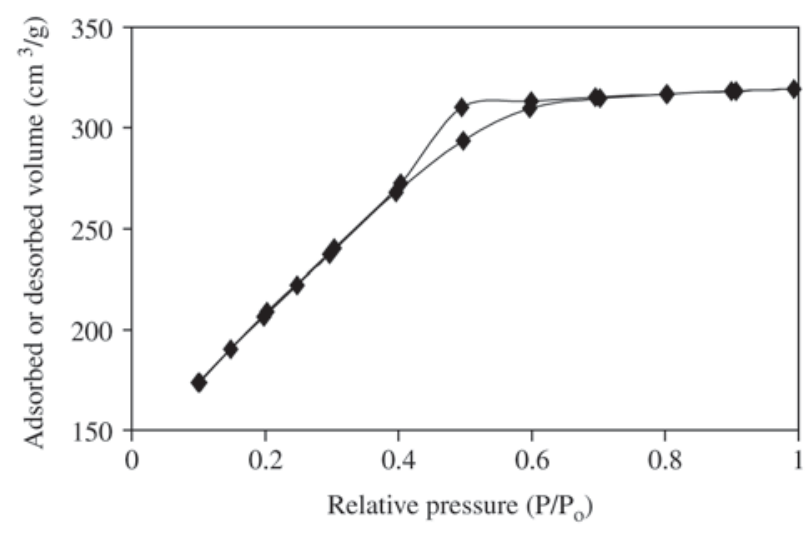

Figure 1. Isotherm of $\mathrm{N}_{2}$ adsorption-desorption obtained for the porous silica via conventional heating. 


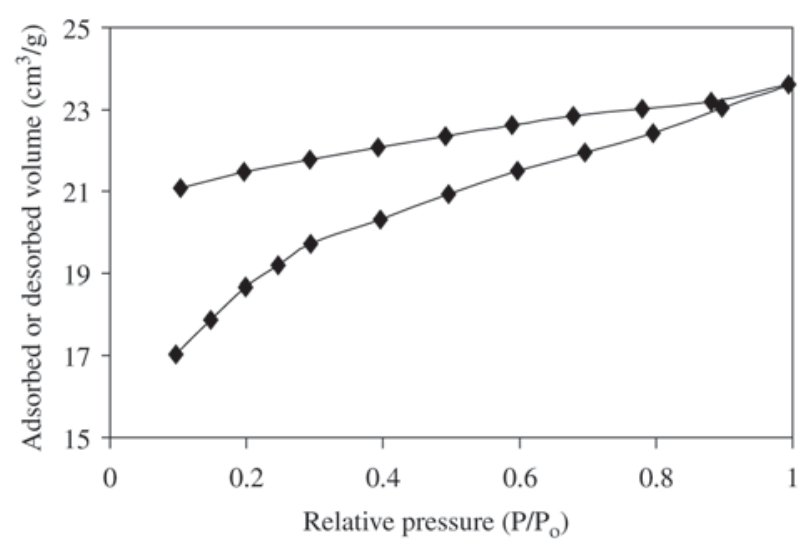

Figure 2. Isotherm of $\mathrm{N}_{2}$ adsorption-desorption obtained for porous silica via microwave heating.

BET theory ${ }^{16}$. The isotherm obtained with microwave heating exhibited unsual shape ${ }^{4}$. This isotherm have an histeresis in the region of low relative pressure. Analysing only the adsorption branch of the isotherm, we can observe that the microwave-processed gel also present a microporous structure. The presence of the pronounced histeresis can be a result of a high proportion of mesoporous and porous with complex geometries ${ }^{15}$.

Figure 3 shows the pore size distributions for silica gels obtained via conventional and microwave heating. The narrow pore size distribution observed is appropriate for using the silica gels in separation processes. For the porous silica obtained via microwave heating we observed a slightly broader pore size distribution, confirming the coexistence of micro and mesopores.

Table 2 shows the data obtained for specific surface area of pores $\left(\mathrm{S}_{\mathrm{p}}\right)$, specific volume of pores $\left(\mathrm{V}_{\mathrm{p}}\right)$ and average pore radius $\left(r_{\mathrm{p}}\right)$ for porous silica fabricated via conventional and microwave heating. The silica gels obtained via microwave heating present specific surface area of pores and specific volume of pores quite smaller than for silica gels obtained via conventional heating. The microwave radiation has strong influence on silica gels structure. Silica gel processed by microwave heating have different pore structure, with smaller microporous area and high bulk density than the conventional-processed gel. This difference can be a result of radiation action on the sol-gel reactions kinetics, leading to a more condensed network.

Table 3 presents the data on volume fraction $\left(\mathrm{V}_{\mathrm{v}}\right)$, surface area density $\left(S_{v}\right)$ and genus $\left(G_{v}\right)$ for the porous silica gels. We observed that $G_{v}$ presented high values, in the order of magnitude of $10^{19}$, for gel made via conventional heating, and $G_{v}$ in the order of $10^{18}$ for gel obtained via microwave heating. The high pores connectivity of silica

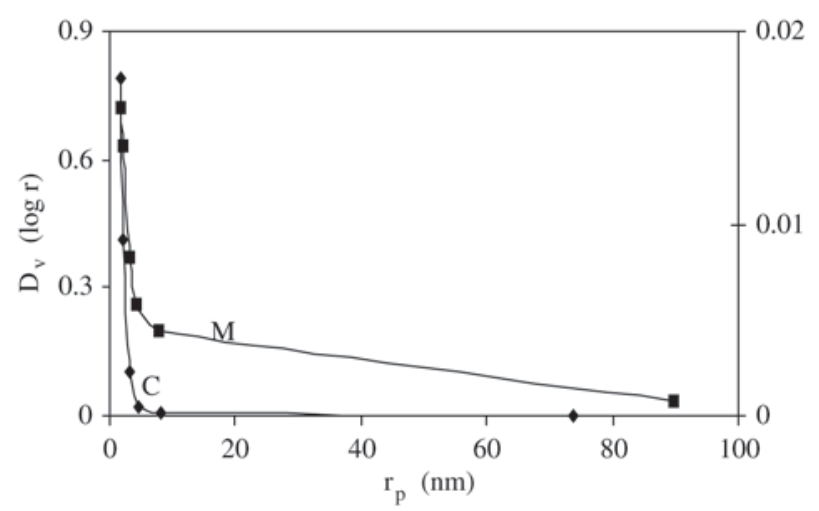

Figure 3. Pore size distribution for porous silica obtained via conventional $(\mathrm{C})$ heating and via microwave $(\mathrm{M})$ heating.

Table 2. Structural parameters of silica gels.

\begin{tabular}{lccc}
\hline Material & $\mathrm{S}_{\mathrm{p}}\left(\mathrm{m}^{2} / \mathrm{g}\right)$ & $\mathrm{V}_{\mathrm{p}}\left(\mathrm{cm}^{3} / \mathrm{g}\right)$ & $\mathrm{r}_{\mathrm{p}}(\mathrm{nm})$ \\
\hline conventional & $748 \pm 37$ & $0.49 \pm 0.02$ & $1.3 \pm 0.07$ \\
microwave & $112 \pm 6$ & $0.07 \pm 0.004$ & $1.2 \pm 0.06$ \\
\hline
\end{tabular}

Table 3. Metric and topological parameters of silica gels.

\begin{tabular}{lcccc}
\hline Material & $\begin{array}{c}\mathrm{S}_{\mathrm{v}} \\
\left(10^{6} \mathrm{~cm}^{-1}\right)\end{array}$ & $\mathrm{V}_{\mathrm{v}}$ & $\begin{array}{c}\mathrm{r}_{\mathrm{p}} \\
(\mathrm{nm})\end{array}$ & $\begin{array}{c}\mathrm{G}_{\mathrm{v}} \\
\left(10^{19} \mathrm{~cm}^{-3}\right)\end{array}$ \\
\hline conventional & $10.5 \pm 0.9$ & $0.69 \pm 0.06$ & $1.32 \pm 0.07$ & $5.46 \pm 2.3$ \\
microwave & $2.0 \pm 0.2$ & $0.13 \pm 0.01$ & $1.24 \pm 0.06$ & $0.22 \pm 0.09$ \\
\hline
\end{tabular}

gels show the feasibility of using these materials in separation or adsorption processes ${ }^{13}$.

The thermogravimetric analyses show that the porous silica obtained via conventional heating presented higher water content when compared with the water content of the porous silica obtained via microwave heating. The water content was approximately $36 \%$ for gel obtained via conventional heating and $15 \%$ for gel made via microwave heating. This result is related to the high specific surface area of pores for gel obtained via conventional heating when compared with the specific surface area of pores for gel obtained via microwave heating. Those high values favor the presence of silanol groups in that gel. Figure 4 exhibits the thermogrametric curves for the porous silica obtained. We observed two different regions of weight loss for the gel obtained via conventional heating. The first region corresponds to temperatures below $150{ }^{\circ} \mathrm{C}$ and is associated to loss of structural water. The second region occurs at temperatures above $300{ }^{\circ} \mathrm{C}$. For the gel obtained via micro- 


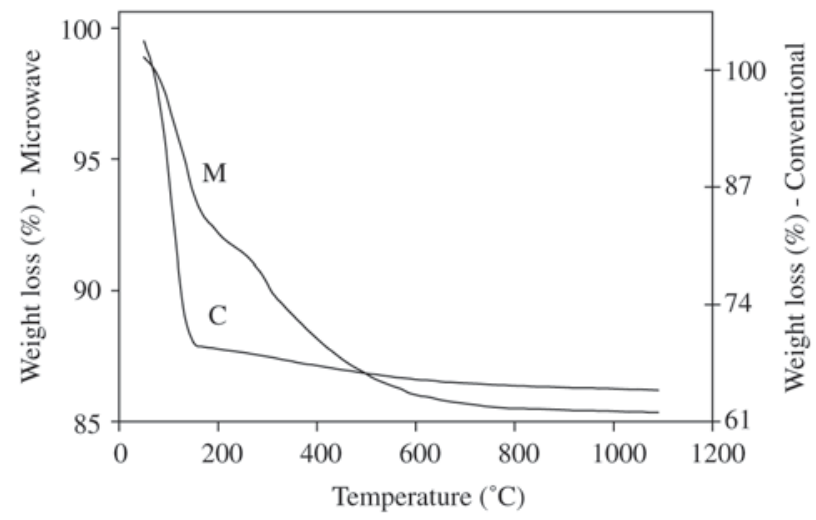

Figure 4. Thermogravimetric analyses of silica gels obtained via conventional $(\mathrm{C})$ heating e via microwave $(\mathrm{M})$ heating.

wave heating, Fig. 4 shows three different regions of weight loss: at temperatures below $180^{\circ} \mathrm{C}$ and at temperatures between $230{ }^{\circ} \mathrm{C}$ and $300{ }^{\circ} \mathrm{C}$, which corresponds the loss of structural water; and above $300{ }^{\circ} \mathrm{C}$, which corresponds to simultaneous loss of carbon residues and also to the loss of structural water in the form of silanol groups.

Figure 5 shows curves of differential thermal analyses (DTA) for gels obtained via conventional and microwave heating. We observed an endothermic peak, which can be attributed to evaporation of molecular water adsorbed on gels surface. We noted that the endothermic peak intensity is bigger for the curve of gel obtained via conventional heating. The information obtained with differential thermal analyses (DTA) confirmed the results obtained by TGA. The porous silica obtained via conventional heating present higher water content when compared with the water content of the porous silica obtained via microwave heating.

With infrared spectroscopy it was possible to analise the interactions involved and the structure of silica fabricated by sol-gel processing. The use of FTIR intended to verify the difference resulting from the variation of processing parameters for materials fabricated via conventional heating and microwave heating.

Figure 6 shows the spectra obtained for FTIR analyses of the porous silica fabricated via conventional heating and using microwave heating. In the region between $3700 \mathrm{~cm}^{-1}$ and $2700 \mathrm{~cm}^{-1}$ occurs the absorption corresponding to the presence of silanol groups $(\mathrm{Si}-\mathrm{OH})$ and water. In this region occurs a variety of absorption frequencies, due to the variety of structures and interactions involved.

The peaks located around $1970 \mathrm{~cm}^{-1}, 1860 \mathrm{~cm}^{-1}$ and $800 \mathrm{~cm}^{-1}$ are characteristics of Si-O-Si bonds of the silica network and these bonds appear in the spectrum of fused silica ${ }^{17}$. The peak at around $1630 \mathrm{~cm}^{-1}$ corresponds to the

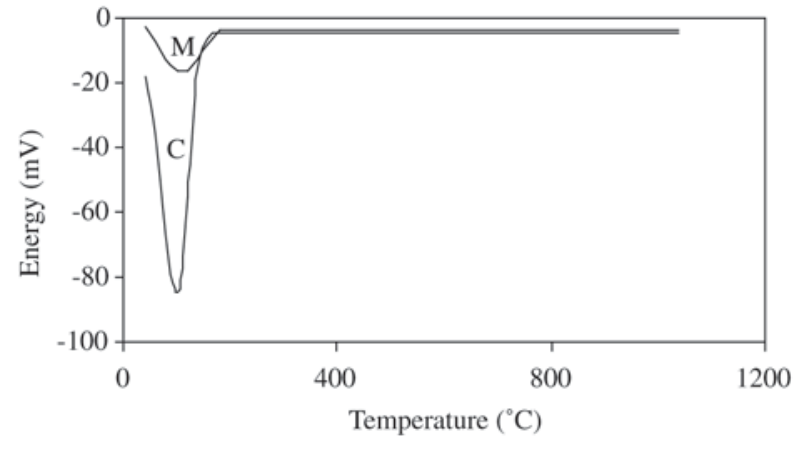

Figure 5. Differential thermal analyses of silica gels obtained via conventional $(\mathrm{C})$ heating and via microwave $(\mathrm{M})$ heating.

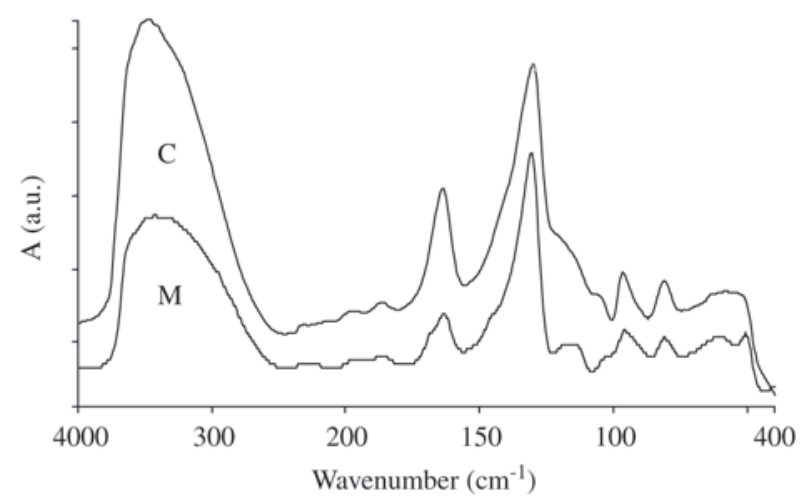

Figure 6. FTIR spectra of silica gels obtained via conventional (C) heating and via microwave (M) heating.

absorption for molecular water incorporated in the structure and tends to disappear after heat treatment at high temperatures. Differences in magnitude observed for peaks corresponding to molecular water and silanol groups $\left(1630 \mathrm{~cm}^{-1}, 2700-3700 \mathrm{~cm}^{-1}\right)$ confirm the high proportion of water incorporated into the porous silica obtained via conventional heating, as determined by TGA analyses.

The absorption band between $1200 \mathrm{~cm}^{-1}$ and $1000 \mathrm{~cm}^{-1}$ corresponds to $\mathrm{Si}-\mathrm{O}-(\mathrm{Si})$ stretching vibration associated to linear structures of glass network ${ }^{18}$. We observed that the spectrum of silica gels obtained via microwave heating presented this band at larger wavelengths. This represents a more branched network, with a larger proportion of $\mathrm{Si}-\mathrm{O}-(\mathrm{Si})$ bonds associated to cyclic structures ${ }^{18}$. The peak at about $960 \mathrm{~cm}^{-1}$ corresponds to stretching vibration of $\mathrm{Si}-\mathrm{O}(\mathrm{H})$ bonds and we can observe by Fig. 6 that this peak appears at a higher wavelength in the spectrum of gel obtained via microwave heating, indicating that this bond belongs to a more branched silica network. This result con- 
firms that microwave radiation acts towards the increasing in the extension of polymerization reactions, leading to a more condensed network, with a higher bulk density, smaller surface area and pore volume, and a higher number of cross link than the conventional-treated gel.

\section{Conclusions}

Microwave radiation affects sol-gel materials structure, as was demonstred by $\mathrm{N}_{2}$ adsorption-desorption isotherms and density measurements. The gel obtained via microwave radiation presents higher density and smaller surface area than the gel obtained via conventional heating. Through the analyses of TGA, DTA and FTIR we observed that porous silica obtained via conventional heating presents higher water content than the gel obtained via microwave heating. According to FTIR analyses we observed that the silica obtained via microwave heating presents a more branched pore network than the pore structure of silica obtained with conventional heating.

\section{Acknowledgments}

The authors thank CNPq, CAPES and FAPEMIG for financial support.

\section{References}

1. Sutton, W.H. Bulletin of the American Ceramic Society, v.68, n.2, p.376, 1989.

2. Clark, D.E.; Folz, D.C. Ceramic Engineering and Science Proceedings, v.18, n.4, p.531, 1997.

3. Mingos, D.M.P.; Baghurst, D.R. Chemical Society Reviews, v.20, n.1, p.1, 1991.

4. Ferreira, M.P. Uso da Radiação Eletromagnética (Microondas, Ultravioleta e Raios Gama) e do Campo Magnético no Processamento Sol-gel da Sílica,
Universidade Federal de Minas Gerais, 2000, 177p. (Ph.D Thesis).

5. Schmidt, H. Journal of Non-Crystalline Solids, v. 100, p. 51, 1988.

6. Hench, L.L.; Vasconcelos, W.L. Annual Review of Materials Science, Palo Alto, v. 20, p. 269, 1990.

7. Lenza, R.F.S.; Vasconcelos, W.L. Mat. Res., v.4, n.3, p. 189, 2001.

8. Lenza, R.F.S.; Vasconcelos, W.L. Mat. Res., v.4, n.3, p. 175, 2001.

9. Di Fiori, R.R.; Clark, D.E. Ceramic Engineering and Science Proceedings, v.16, p. 1089, 1995.

10. Rajeshkumar, S.; Anilkumar, G.M.; Ananthakumar, S.; Warrier, K.G.K. Journal of Porous Materials, v.5, p.59, 1998.

11. Park, S.; Kim, D.S.; Chang, J.; Kim, W.Y. Catalysis Today, v.44, p.301, 1998.

12. Zhong, J.P.; Fathi, Z.; La Torre, G.P.; Folz, D.C.; Clark, D.E.; Ceramic Engineering and Science Proceedings, v.15, p.1003, 1994.

13. Lenza, R.F.S.; Vasconcelos, W.L. Journal of Non-Crystalline Solids, v.263, n.1-3, p.164, 2000.

14. Vasconcelos, W.L.; DeHoff, R.T.; Hench, L.L. Journal of Non-Crystalline Solids, v.121, n.3, p.124, 1990.

15. DeBoer, J.H. The Structure and Proprieties of Porous Materials, Butterworths, London, p. 68, 1958.

16. Brinker, C.J.; Scherer, G.W. Sol-Gel Science: The Physics and Chemistry of Sol-Gel Processing, Academic Press, inc. San Diego, CA. p. 907, 1990.

17. Orcel, G.; Phalippou, J.; Hench, L.L. Journal of NonCrustalline Solids, v.88, p.114, 1986.

18. FTIR Study, Study of the formation mechanisms of SolGel Silica - Influence of Formamida, http://friss.ustrasburg.fr/english/gmi/viarth/webposter/ftir/ftir.html. 04/11/1997. 